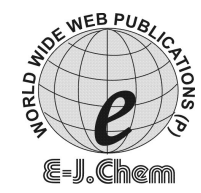

http://www.e-journals.net

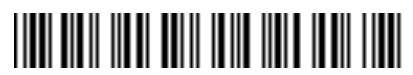

ISSN: 0973-4945; CODEN ECJHAO

E-Journal of Chemistry

Vol. 4, No. 4, pp. 606-610, October 2007

\title{
Mild and Efficient One Pot Synthesis of Imidazolines and Benzimidazoles from Aldehydes
}

\author{
RAJESH KUMAR and Y. C. JOSHI* \\ *Department of Chemistry, \\ University of Rajasthan, Jaipur-302004, India \\ rnunia@yahoo.com
}

Received 28 April 2007; Accepted 1 June 2007

\begin{abstract}
A series of some imidazolines and benzimidazoles were synthesized from various aldehydes and 1,2-diamines in the presence of ceric(IV) ammonium nitrate (CAN). The title compounds were prepared via one step synthesis method. The simplicity of the reaction conditions with shorter reaction time and with out use of column chromatography to get the pure products in high yields makes this method more attractive for organic chemists.
\end{abstract}

Keywords: Ceric(IV) ammonium nitrate; Imidazolines; Benzimidazole.

\section{Introduction}

Heterocycles form by far the largest of classical divisions of organic chemistry and are of immense importance biologically and industrially. The majority of pharmaceuticals and biologically active agrochemicals are heterocyclic while countless additives and modifiers used in industrial applications ranging from cosmetics, reprography, information storage and plastics are heterocyclic in nature. One striking structural features inherent to heterocycles, which continue to be exploited to great advantage by the drug industry, lies in their ability to manifest substituents around a core scaffold in defined three dimensional representations. The development of simple, efficient and environmentally benign chemical processes or methodologies for widely used organic compounds from readily available reagents is one of the major challenges for chemists in organic synthesis. The importance of imidazoline and benzimidazloes, units arises, because they are found in many biologically active compounds ${ }^{1}$. In organic synthesis, imidazoline units are also used as synthetic intermediates $^{2}$, chiral auxiliaries ${ }^{3}$, chiral catalysis ${ }^{4}$ and ligands for asymmetric catalysis ${ }^{5}$. In addition, the benzimidazole moiety is found in various synthetic pharmaceuticals displaying a broad spectrum of biological activity including anti-ulcer, anti-tumor and anti-viral effects ${ }^{6}$. 
A number of methods have been reported for the synthesis of imidazolines and benzimidazoles which include conversion of esters using aluminium reagents ${ }^{7 \mathrm{a}}$, the reaction between $N$-ethoxy carbonylthioamides with 1,2 -diamines ${ }^{7 \mathrm{~b}}$ and the reaction of aldehydes with 1,2-diamines followed by $N$-halosuccinimides $(\mathrm{X}=\mathrm{Cl}, \mathrm{Br}, \mathrm{I})^{7 \mathrm{c}}$. Recently, several method have been developed where azalactones ${ }^{8 \mathrm{a}}, 2$-aryl-1, 1-dibromoethanes ${ }^{8 \mathrm{~b}}$, nitriles ${ }^{8 \mathrm{c}}$ and amino amides ${ }^{8 \mathrm{~d}}$ are used as starting material for this synthesis. However, many of the synthesis protocols reported so far suffer from disadvantages such as needing anhydrous conditions $^{8 \mathrm{a}}$, use of organic solvents ${ }^{7,8}$, harsh reaction conditions $\mathrm{s}^{7 \mathrm{a}}$, prolonged reaction time $^{7 \mathrm{c}}$, use of metals and expensive reagents ${ }^{7 \mathrm{a}}$ etc. Therefore the development of a cost effective, safe and environment friendly reagent system is desirable. Ceric ammonium nitrate (CAN), was introduced by Smith et $a l^{9}$. in 1936. CAN have been received considerable attention as an inexpensive and easily available catalyst of various organic reactions such as oxidation, oxidative-cyclization, nitration, photo-oxidation, deprotection and graft polymerization ${ }^{10}$.

\section{Experimental}

All yields refer to isolated product after purification. All the products were confirmed by comparison with authetic sample (IR, TLC, NMR, and MS). IR spectra were recorded on Perkin Elmer 1700 Specrophotometer. TLC is performed using precoated aluminium sheets with silica gel $60 \mathrm{~F}_{254}$. ${ }^{1} \mathrm{H}$ NMR spectra were recorded on a Brucker Avance NMR spectrophotometer operating at $400 \mathrm{MHz}$ using tetramethylsilane as an internal standard.

\section{General experimental procedure for the synthesis of imidazolines/benzimidazoles}

To a solution of aldehydes $(1 \mathrm{mmol})$ and 1,2 -diamines $(1 \mathrm{mmol})$ in dry dichloromethane $(5 \mathrm{~mL})$ were added ceric ammonium nitrate $(0.5 \mathrm{mmol})$. The reaction mixture was stirred for 15 minutes at reflux. Water $(5 \mathrm{~mL})$ was added and the mixture was extracted in dichloromethane $(3 \times 5 \mathrm{~mL})$. The solvent was evaporated and crude product was recrystallized from dichloromethane give the desired product (Table 1).

Table 1. Synthesis of imidazolines and benzimidazoles from aldehydes and 1,2- Diamines.

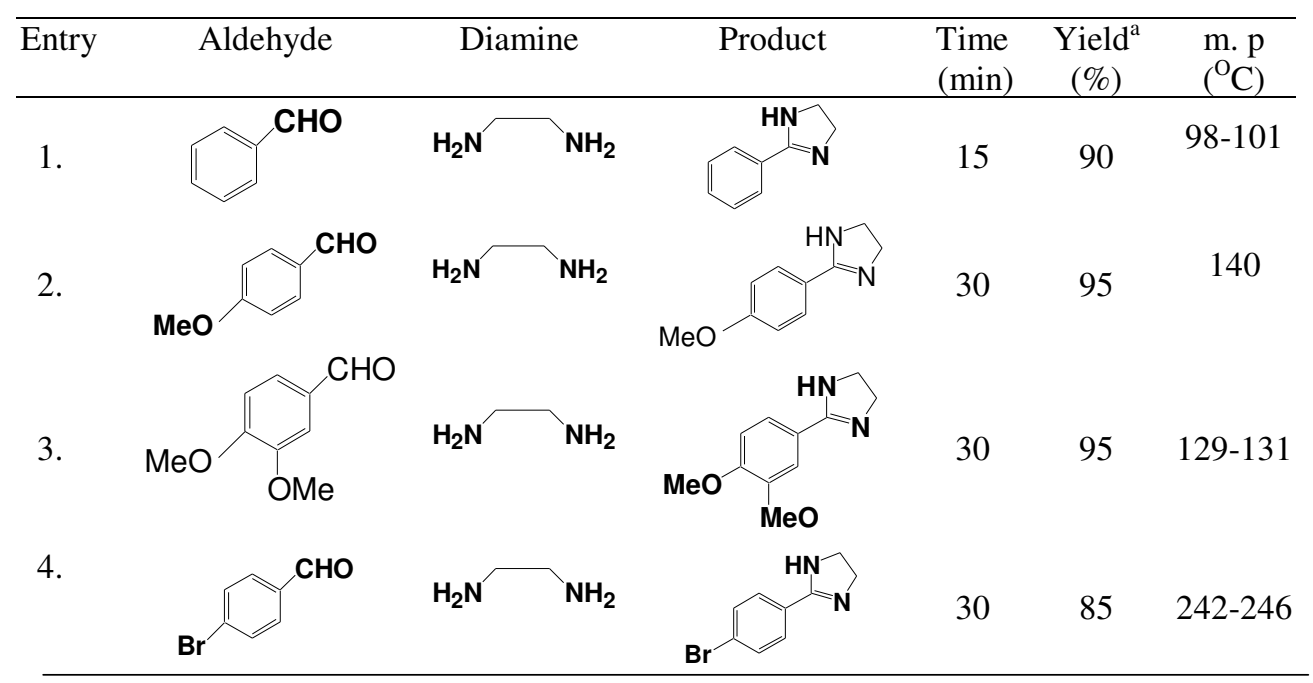




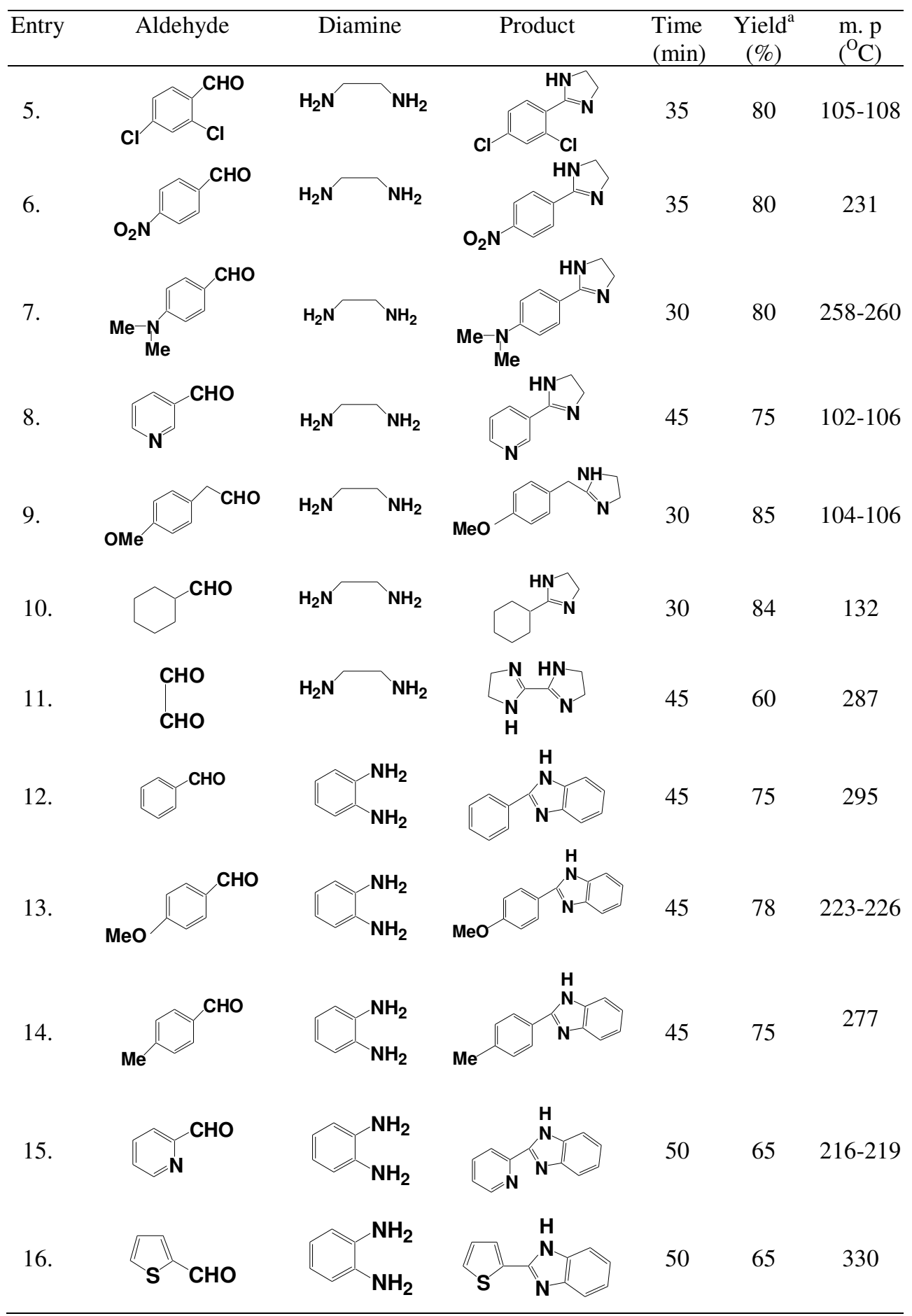

All the products gave satisfactory NMR, IR and MS data. ${ }^{a}$ Isolated yield 


\section{Results and Discussion}

As a part of our ongoing investigation as developing versatile and efficient method for synthesis of heterocyclic compounds. We report here a synthetic method of imidazoines and benzimidazole from aldehydes and 1, 2-diamines in presence of CAN.

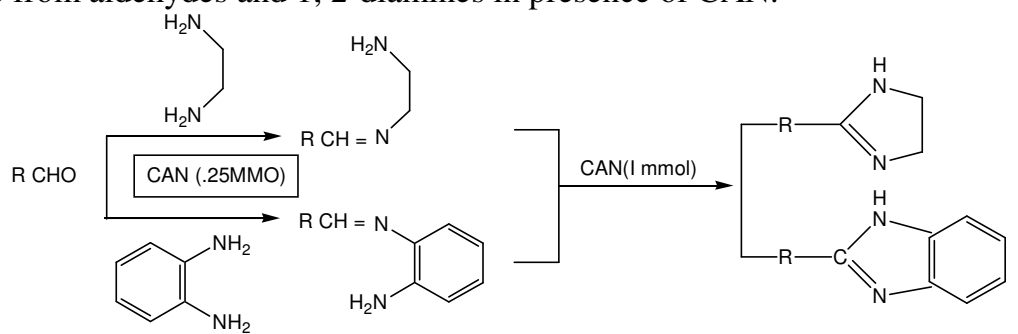

Scheme 1. Synthesis of imadozolines and benzimidazoles.

First, the synthesis of imadozolines and benzimidazoles was investigated through a two way. We examined a number of different substituted aldehydes and 1,2-diamines were reflux with catalytic amount of CAN. We were pleased to find that to high yield were sustained for coupling of virtually all aldehydes and 1,2-diamines. The coupling product under went cyclization - oxidation using CAN under solvent free conditions (Scheme 1). This occurred in 20 min under mild condition at room temperature. But in one pot when aldehydes and 1,2-diamines were stirred in dichloromethane under reflux at $50{ }^{\circ} \mathrm{C}$ for $15 \mathrm{~min}$ in presence of CAN, the corresponding imidazolines and benzimidazoles were obtained good yield (Scheme 2 )

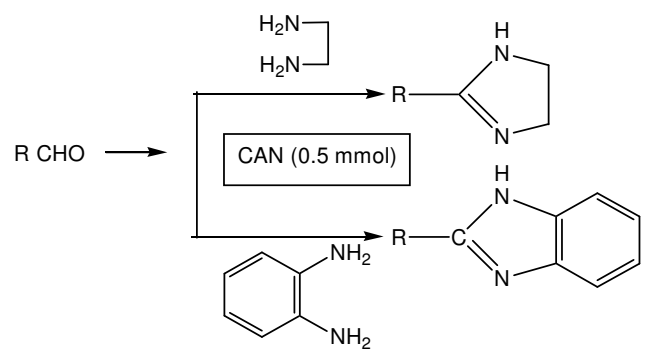

Scheme 2. One pot synthesis of imidazolines and benzimidazoles

Regarding the mechanism of oxidation step, it is proposed (Scheme 3) that the imidazoline and benximidazoles.

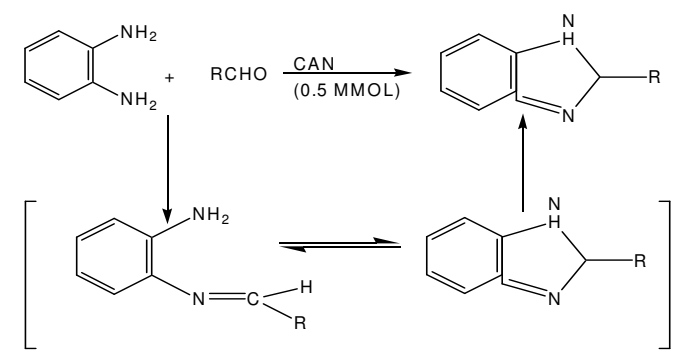

Scheme 3. Possible mechanism and tentative intermediates in the synthesis of imidazolines and benzimidazolines.

In conclusion, the present synthetic method is a simple efficient, inexpensive and easy synthesis of biologically active imidazolines and benzimidazoles via an oxidation process with CAN. 


\section{Acknowledgements}

Authors are thankful, to Head Department of Chemistry, University of Rajasthan, Jaipur for providing Laboratory facilities. One of them (Rajesh Kumar) is thankful to the UGC for the award of senior research fellowship.

\section{References}

1. (a) Grimmett M R, In Comprehensive Heterocyclic Chemistry, Katcizky A R, Rees C W, Scriven E F V, Eds, Pergamon: Oxford, 1996,Vol. 3, pp 77-220. (b) Greenhill J V, Lue L, In Progress in Medicinal Chemistry, Ellis G P, Luscombe D K, Eds, Elsevier: New York, 1993, Vol. 3.(c) Preston P N, Chem. Rev.1974, 74, 179-314. (d) Touzeau F, Arrault A, Guillaumet G, Scalbert E, Pfeiffer B, Rettori M C, Renard P and Merour J Y J. Med. Chem.. 2003, 46, 1962-1979. (e) Roundu F, Bihan G L, Wang X, Lamouri A, Touboul E, Dive G, Bellahsene T, Pfeiffer B, Renard P, Guardiola-Lemaitre B, Manechez D,Penicaud L, Ktorza A and Godfroid J J, J. Med. Chem. 1997, 40, 3793-3803.

2. (a) Jones R C F and Nichols J R Tetrahedron Lett. 1990, 31, 1771. (b) Jones C, Smallridge M J and Chapleo C B J. Chem. Soc., Perkin Trans. 1991, 385. (c) Hayashi T, Kishi E, Soloshonok V A and Uozumi Y, Tetrahefron Lett. 1996, 37, 4969 . (d) Lin Y R, Zhou X T, David L.-X and Sun J J. Org. Chem. 1997, 62, 1799. (e) Hsiao Y and Hegedus L S J. Org. Chem. 1997, 62, 3586. (f) Jung M E and Huang A Org. Lett. 2000, 2, 2659- 2661.

3. (a) Jonesv R C F, Turner I and Howard K J Tetrahedron Lett. 1993, 34, 63296332. (b) Langlois Y and Dalko P I J. Org. Chem. 1998, 63, 8107-8117. (c) Jones R C F and HowardSnaith K J, Tetrahedron Lett. 1996, 37, 1707-1710.

4. (a) Corey E J and Grogan M J Org. Lett. 1999, 1, 157-160. (b) Isober T, Fukuda K, Araki Y and Ishikawa T, Chem. Commun, 2001, 243-244.

5. (a) Botteghi C, Schionato A, Chelucci G, Brunner H, Kurzinger A and Obermann U J. Organomet. Chem. 1989, 370, 17-31. (b) Morimoto T, Tachibana K and Achiwa K Synlett, 2003 , 783-785.(c) Davinport A .J, Davies D L, Faweett J and Russell D R J. Chem. Soc., Perkin Trans, 2001, 1, 1500-1503. (d) Menges F, Neuburger M and Pfaltz A Org. Lett. 2002, 4, 4713-4716. (e) Boland N A, Casey M, Hynes S J, Matthews J W Muller-Bunz H and Wilkes P Org. Biomol. Chem. 2004, 2, 1995-2002.

6. (a) Preston P N, Stevens M F G and Tennant G Benzimidazoles and Congeneric Tricyclic Compounds, Part 2, John Wiley \& Sons: New York , 1980. (b) Cedillo-River $\mathrm{R}$ and Munoz O J. Med. Microbiol, 1992, 37, 221-224. (c) Chavez B, Cedillo-Rivera R and Martiner-Palomo A J. Protozool, 1992, 39, 510-515. (d) Navarrete-Vazquez G, Cedillo R, Hernandez-Campos A, Yepez L, Hernandez-Luis F, Valdez J, Morales R Cortes R Hernandez M and Castillo R Bioorg. Med. Chem. Lett. 2001, 11, 187-190.

7. (a) Neef G, Eder U and Sauté G, J. Org. Chem. 1981, 46, 2824-2826. (b) George B and Papadopoulos E P J. Org. Chem. 1977, 42, 441-443. (c) Fujioka H, Murai K, Ohab Y, Hiramatsu A and Kita Y, Tetrahedron Lett. 2005, 46, 2197-2199.

8. (a) Peddibhotla S and Tepe J J Synthesis 2003,1433-1440. (b) Huh D H, Ryu H and Kim Y G, Tetrahedron, 2004, 60, 9857-9862. (c) MitchellJ M and Finney N S, Tetrahedron Lett. 2000, 41, 8431-8434. (d) You S Land Kelly J W,Org. Lett. 2004, 6, 1681.

9. Smith G F, Sullivan V R and Frank G Ind. Eng. Chem. Anal. Ed. 1936, 8, 449-451.

10. (a) Molander G A, Chem. Rev. 1992, 92, 29-68. (b) Hwu J R and King K Y Curr. Sci. 2000, 81, 1043. (c) Hwu J R, Shaio S S and Hakimelahi G H Appl. Organmet. Chem..1997, 11, 381. (d) Hwu J R, Chem C N and Shaio S S J. Org. Chem. 1995, 60, 826. (e)Hwu J R, Chem K L S and Ananthan, S J. Chem. Soc. Chem. Commun. 1994, 1925. 


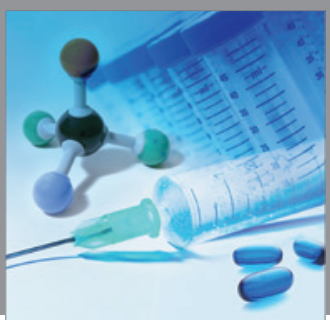

International Journal of

Medicinal Chemistry

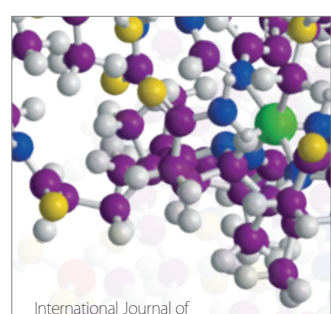

Carbohydrate Chemistry

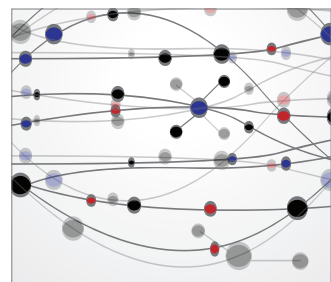

The Scientific World Journal
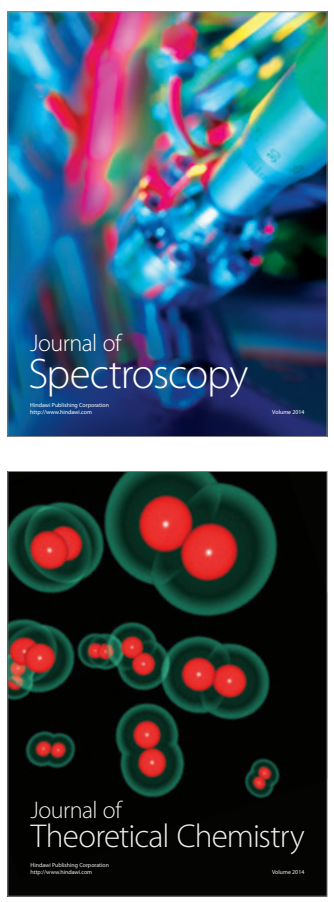
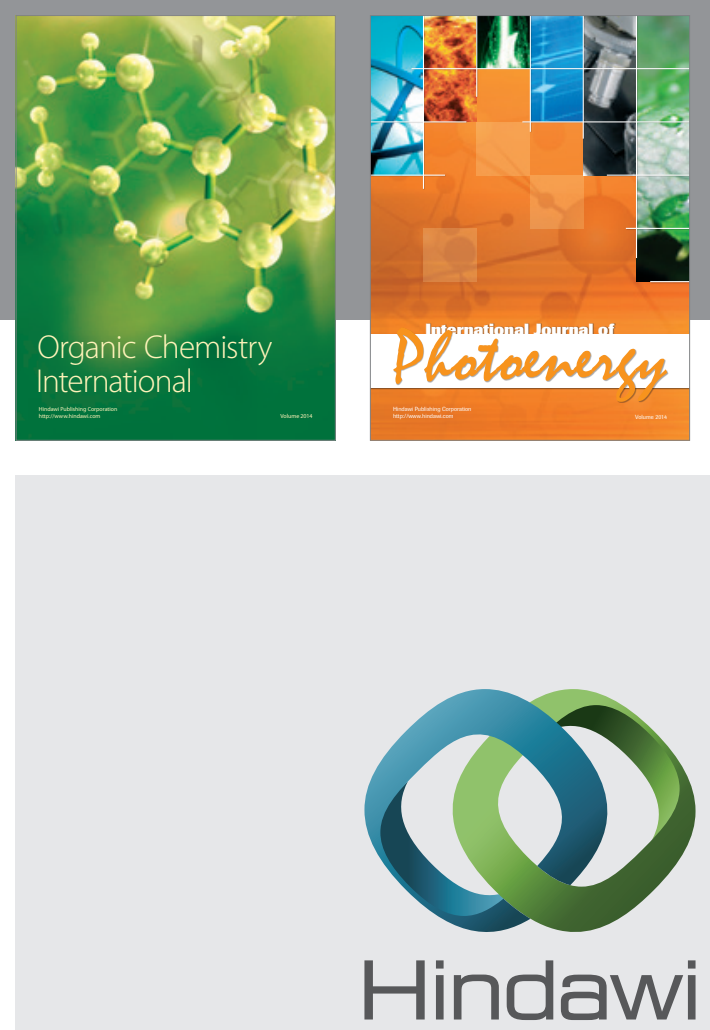

Submit your manuscripts at

http://www.hindawi.com
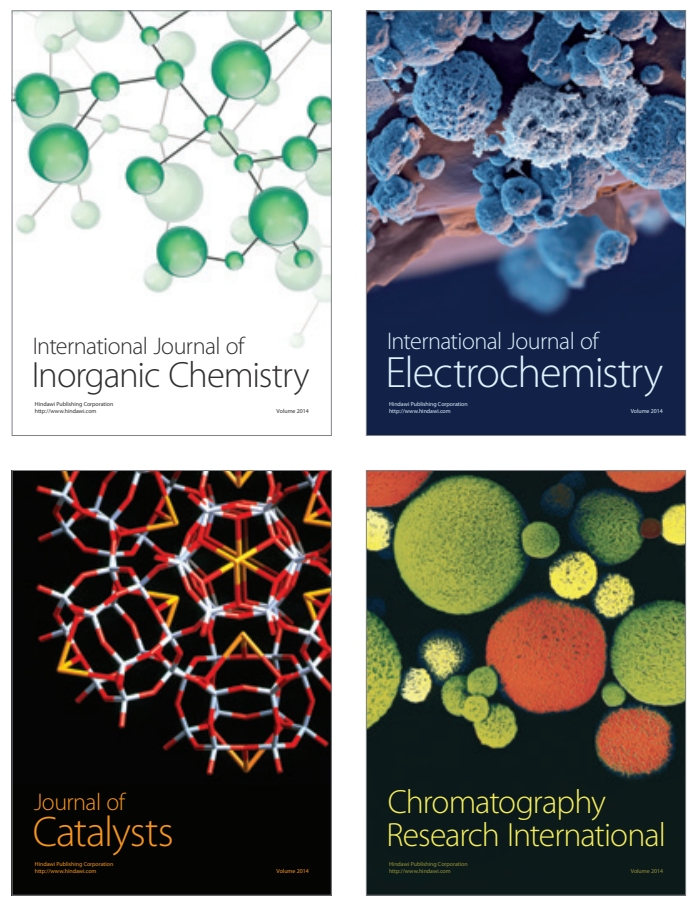
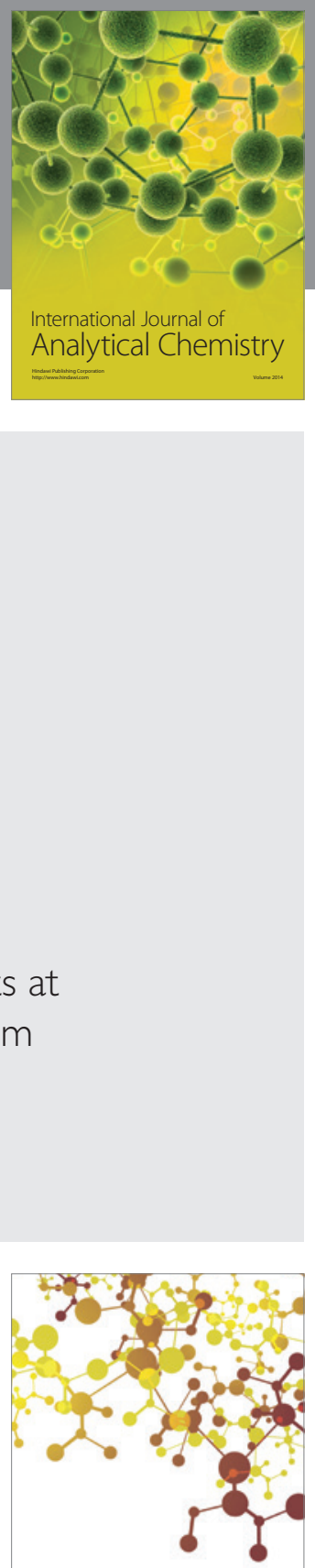

Journal of

Applied Chemistry
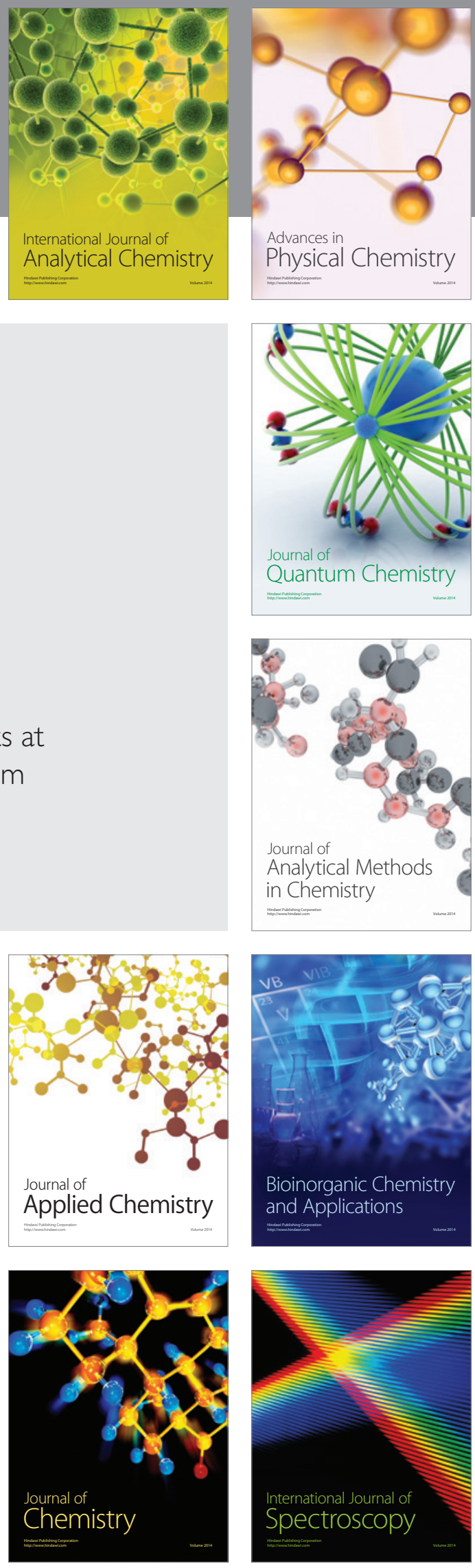